\title{
Design and Analysis of Rescue Robot using Micro Controller and Zigbee Technology
}

\author{
S. Prasanna, K. Vaishnavi, M. Mahalakshmi, P. Niranjana, R. Vinitha Kumari
}

\begin{abstract}
Intelligent rescue systems with required information and robot technology have been predicted to alleviate disaster damages. According to an international survey report, a child is losing his/her life by getting fallen in a borehole which is left uncovered is increasing day by day. The main objective of this paper is to introduce a robot which is named as rescue robot which helps to rescue the life from the borehole safely and the various methods to process this implementation. There are many methods available to rescue the child from borehole in which a human should get into the borehole through an alternate way or by impart the machineries which may cause damage to the child as well as to the land also. To avoid these major problems, this paper introduces a rescue robot which shows the child's condition inside the borehole lively by video camera as well as the methods to rescue the child from the borehole without causing any damage to the life or land. This robot is designed by using the major components such as Zigbee technology, servo motor, micro controller, video camera and laser.
\end{abstract}

Keywords: Recue Robot, Zigbee, Servo motor, Video camera, Micro controller, Laser.

\section{INTRODUCTION}

This rescue robot is a human controlled robot which provides the live information of the process of rescuing the child safely from the borehole. This robot is designed in a way to rescue the child from the borehole in which the robot can able to move inside the borehole according the commands passed by the controller through PC. Since robots are very useful for manipulating the controlled environments. Robotics concept is one of the major and familiar in Artificial Intelligence. This implementation explains the new technology for rescue the child from the borehole. Recently, many accidents report on children falling in open borehole is increasing. Among those, only few are rescued safely. To overcome those issues, we have a feasible solution.

Revised Manuscript Received on April 18, 2020.

* Correspondence Author

Dr. Mrs. S. Prasanna*, Assistant Professor, Department of Computer Science, Shri SSS Jain College for Women, Chennai, India.Email: s.prasana@shasuncollege.edu.in

Ms. K. Vaishnav, Research Scholar, M Phil (Computer Science), Shri SSS Jain College for Women, Chennai, India.Email :vaishuangel25.7@gmail.com

M. Mahalakshmi, II M.Sc (Computer Science), Shri SSS Jain College for Women, Chennai, India.Email :mahalakshmi04091997gmail.com

P. Niranjana, II M.Sc (Computer Science), Shri SSS Jain College for Women, Chennai, India.Email :niranjanapavi@gmail.com

R. Vinitha Kumari, II M.Sc (Computer Science), Shri SSS Jain College for Women, Chennai, India.Email :vinipumba123@gmail.com

(C) The Authors. Published by Blue Eyes Intelligence Engineering and Sciences Publication (BEIESP). This is an open access article under the CC BY-NC-ND license (http://creativecommons.org/licenses/by-nc-nd/4.0/)
This project is one of those feasible solutions which can rescue the child easily without causing any damage to the child as well as to the land. Since this robot is a light weight machine which can easily go inside the borehole and can trap and lift the child using servo motor in its arm.

\section{OBJECTIVE OF IMPLEMENTATION OF RESCUE ROBOT:}

The main objectives of this implementation include:

1. Rescue Robot can be controlled through PC using Zigbee technology.

2. This is a Wireless Robot.

3. Situation inside the borehole can be viewed lively by camera connect to it.

4. Using Servo motor, this Robot can easily pick and place the child.

5. By using LED, light can be produced inside the borehole to view the child's situation more clearly[1].

\section{CIRCUIT DIAGRAM FOR RESCUE ROBOT:}

\subsection{Sender Side:}

The below figure 1 illustrates the circuit diagram for the rescue robot on the its communication part from the Personal Computer/Laptop to the robot.

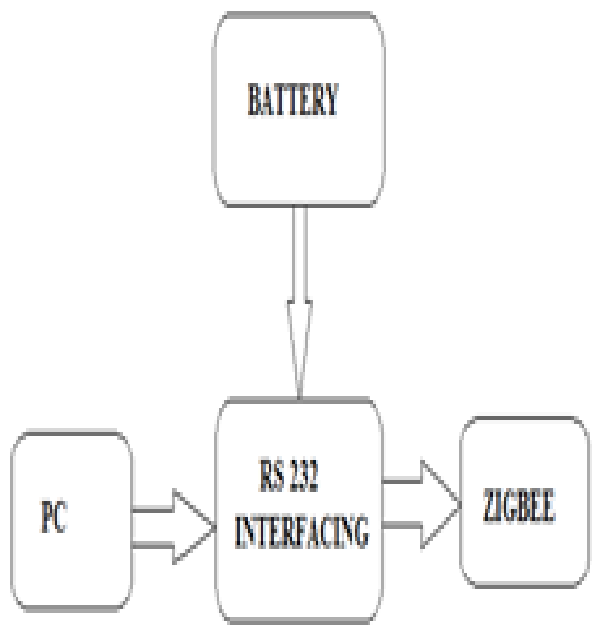

Fig. 1 - Communication From Pc To The Robot

\subsection{Receiver Side:}

The figure 2 illustrates the robot's action inside the bore hole. The figure also depicts the various parts of the robot.

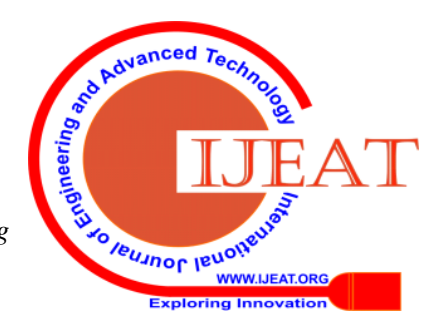




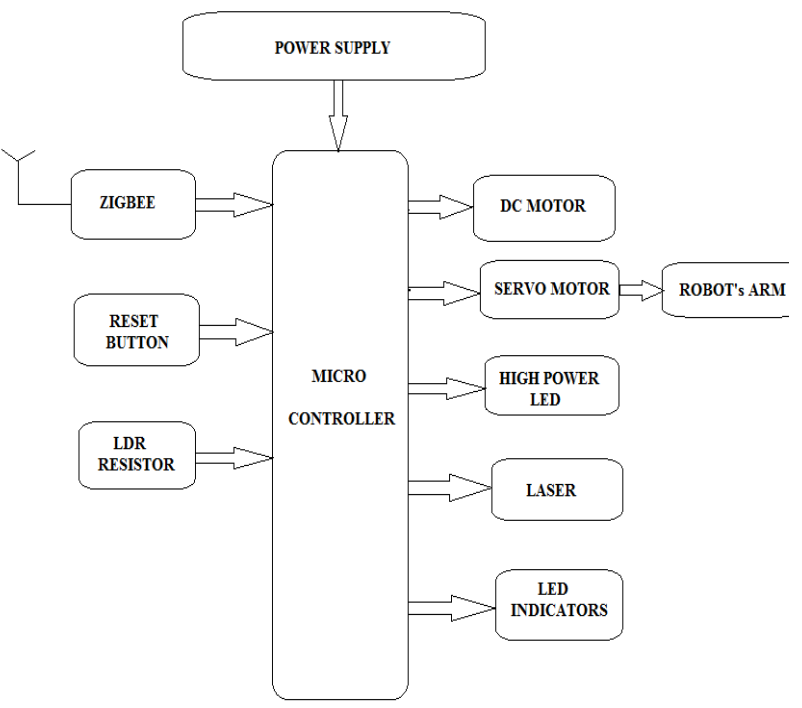

Fig. 2 - Robot's Action Inside The Borehole

\subsection{Battery Consumption:}

The below figure 3 shows that AV transmitter and Video Camera consumes the battery during the functioning of the rescue robot.

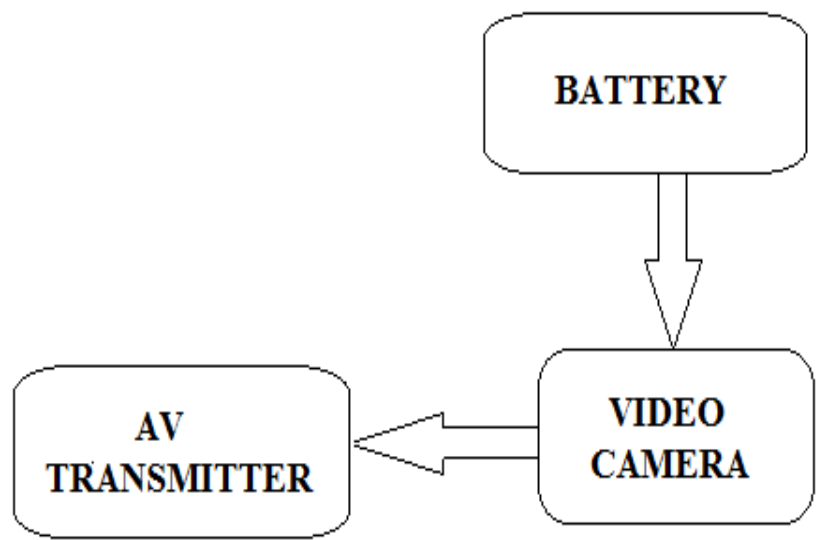

Fig.3 - Battery Consumption By Av Transmitter And Video Camera

\section{HARDWARE COMPONENTS:}

\subsection{Micro Controller:}

Micro controller is a small computer which seems to be compact in an embedded system for a specific operation. It is likely to be seen as a simple CPU with the combination of oscillator, time measurement, I/O devices, etc. Micro controllers are used not only in the concept of robotics as well as in many places like aerospace technology, industrial purposes, high technology, scientific, etc. These micro controllers are designed for particularly small process and also for nano technology also. Micro controllers option from simple 4-bit, 8-bit and 16-bit processors to complex 32-bit and 64-bit processors.

In this research article, micro controller plays an important role. Micro controller is an important component which controls the entire robot as per the commands given through the PC by an operator [2].

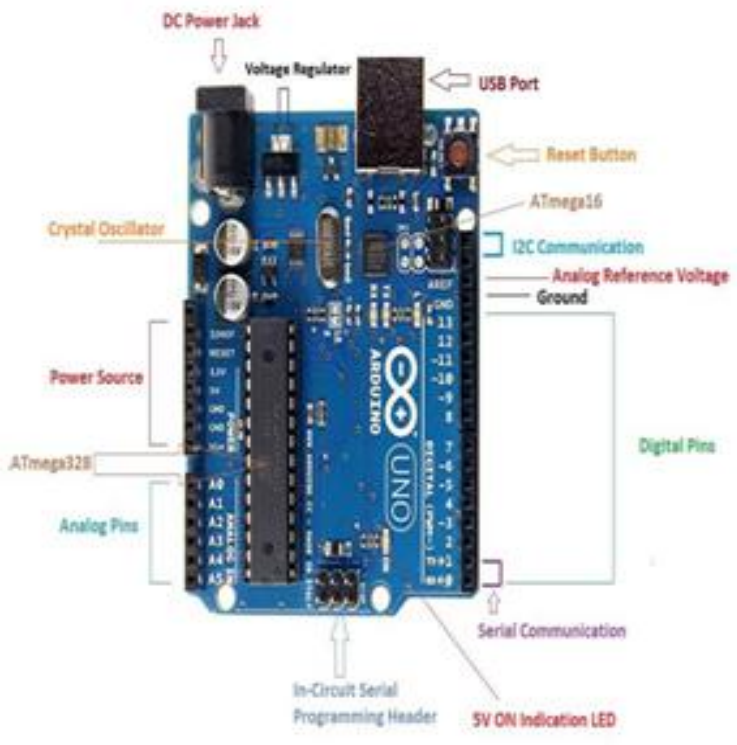

Fig. 4 - Arduino Uno A Micro Controller

\subsection{Zigbee Technology:}

Zigbee technology is a good standard for embedded systems and application software under IEEE 802.15.4 Wireless Networking Standards. Zigbee is specially used for WPAN(Wireless Personal Area Networks) which is less expensive and simple. It mainly works on $2.4 \mathrm{GHz}$ ISM bandwidth $20 \sim 250 \mathrm{kbit} / \mathrm{s}$ data rate, $100 \mathrm{~m} \sim 1.5 \mathrm{~km}$ maximum transmission range, and a typical $100 \mathrm{~m}$ distance.

In this project, Zigbee technology has an ability to mesh network between the nodes. Meshing means daisy chaining from one device to another[3] . A robot can able to follow the instructions provided by the operator in PC by this Zigbee module. This module receives the instructions from the PC to the micro controller to make the robot operate as per the instructions by Bluetooth technology [4] [5].

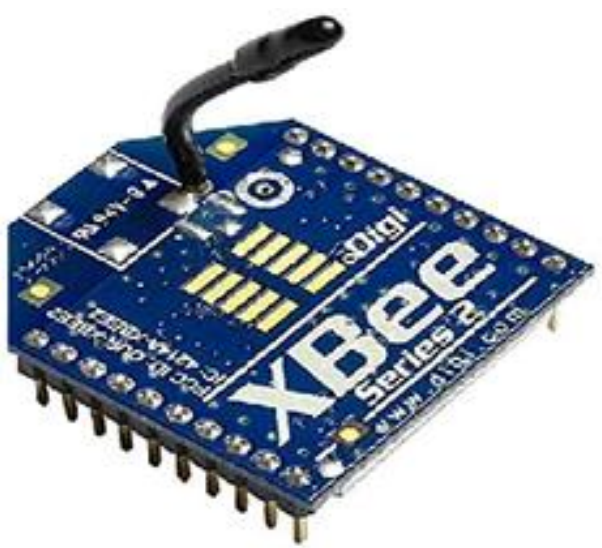

Fig. 5 - Zigbee Device

\subsection{Dc Motor:}

DC motor converts electrical energy into mechanical energy through the interaction of magnetic fields and current - carrying conductors. The vice versa process can be done by the alternate generator or dynamo. The DC motor takes the input as current and produces the output as speed.

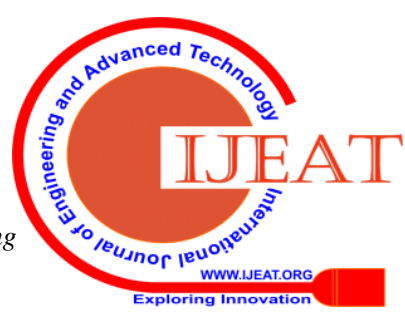


Armature which is a rotating part and field coils are the important basic parts of the DC motor. In this project DC motor is connected as an arm part of the robot which helps to lift the child upwards [6].

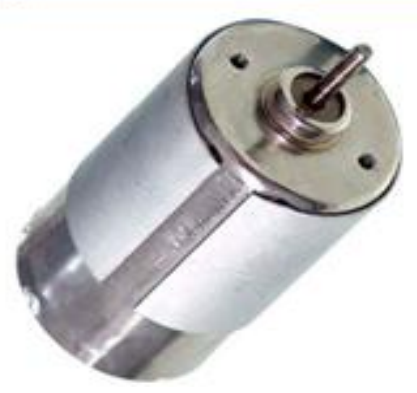

Fig. 6 - Dc Motor

\subsection{Wireless Camera:}

The camera is with 1.2GHZ, with Audio and CMOS and receiver unit with manual frequency adjustment.

1. Linear Transmission Distance: $50-100 \mathrm{~m}$

2. Transmission Signal: Audio, Video

3. Receiving Signal: Audio, Video [7]

\section{WORKING OF A ROBOT:}

Micro controller is the controller of the robot which makes the robot to perform an action with respect to the instructions by the operator through PC. The robot was made to move inside the borehole. If the light is not enough to view the child's condition, with the help of Laser, LDR (Light Dependent Resistor), LED we can able to the view the child.

With the of DC motor which is connected at the arm position of the robot, we can able to instruct the robot to lift up the child. This robot can able to lift a weight approximately $15 \mathrm{~kg}$ to $18 \mathrm{~kg}$. So, there will be no problem to lift the child upwards.

All these instructions are received by the Zigbee technology from the PC through Bluetooth and it help to pass these instructions to the micro controller. So, that the micro controller can able to operate the robot as per the instructions received.

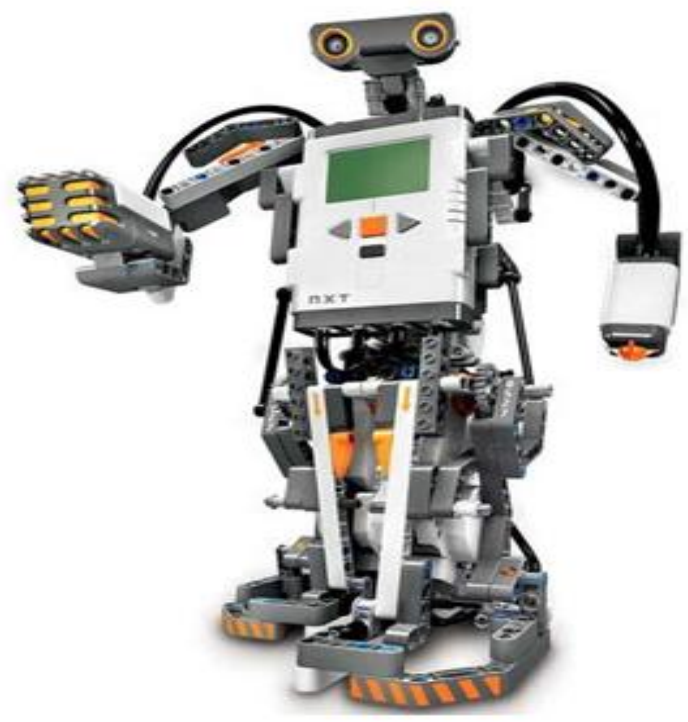

Fig. 7 - Rescue Robot

\section{RESULT}

The project "Rescue Robot using Micro Controller and Zigbee Technology" is developed for the purpose of travelling inside the pipeline to save the child from borehole. An operator can able to operate the robot just by passing the instructions towards the PC. This robot has high power LED light source. Also, it has capability of lifting the weight up to $18 \mathrm{~kg}$. This robot works as a wireless technology which is more useful and easier for operator.

\section{CONCLUSION}

This robot is developed by using the integrated hardware components. This robot should be handled carefully after it make move inside the pipeline to lift the child from borehole. By using highly IC's is an advanced with the help of growing technology. All the components used to develop the robot are micro-chip.

\section{FUTURE SCOPE}

In future, we can able to enhance this robot by connecting:

1. Temperature Sensor which helps to intimates the bad temperature in which a child can't able to be in a borehole. Also, it shows the time limit within how long is there to rescue the child from the borehole live.

2. Smoke Sensor which helps to shows the range of the smokes inside the borehole like coal mines, dangerous gas, etc. which a child can't able to breathe.

\section{REFERENCES:}

1. ShuklaShubhendu S, Jaiswal Vijay, Applicability of Artificial Intelligence in Different Fields of Life, InternationalJournal of Scientific Engineering and Research, pp. 28-35, 2013.

2. R.M.Voyles, S. Povilus, R. Mangharam ,Kang Li. RecoNode: A Reconfgurable Node for Heterogeneous Multi-Robot Search and Rescue. Real-Time and Embedded Systems Lab (mLAB), 2010.

3. Dr. S. Prasanna, Mrs. V. Jeevitha, An implementation of Air Pollution Monitoring using Arduino UNO and Zigbee Technology", International Journal of Research and Analytical Reviews, March 2019, Volume 6, Issue 1, E-ISSN 2348-1269, P - ISSN 2349 5138, Page 1357-1361

4. Chen, H., Chang,L., 2012, Design and Implementation of a ZigBeeBased Wireless Automatic Meter Reading System PrzeglądElektrotechniczny (Electrical Review), pp 64-68

5. www.microchip.com

6. www.allaboutcircuits.com

7. C. Peng, K. Qian, and C. Wang, "Design and Application of a VOC Monitoring System Based on a ZigBee Wireless Sensor Network,' Sensors Journal, IEEE, vol. 15, no. 4, pp. 2255-2268, Apr. 2015.

\section{AUTHORS PROFILE}

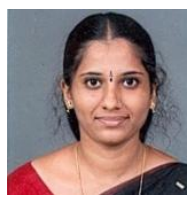

Dr. S. Prasanna MCA, M.Phil, Ph.D is working as an Assistant Professor in the Department of Compute Science, Shri SSS Jain College for Women, Chennai. She has 13 years of research experience and her areas of research include Network Security, Image Processing, and Data Mining. She has published a book on Wireless Adhoc Networks. She has delivered technical talks in Science Academies Refresher courses and published many research articles in International Journals and conferences.

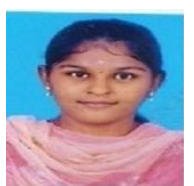

K. Vaishnavi is doing her $\mathrm{M}$. Phil in Compute Science at Shri SSS Jain College for Women, Chennai. $\mathrm{He}$ area of research is Big Data Analytics and Internet of Things.

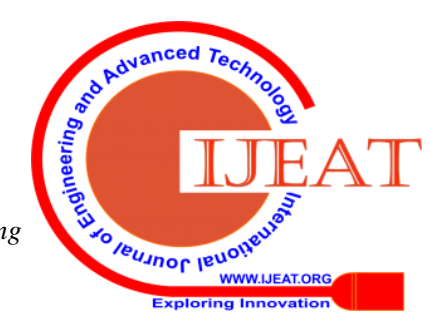


She has developed a Safe Guard Robot using AI \& IoT. She has published research articles in International Journals and Conferences.

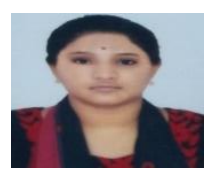

M. Mahalakshmi is doing Master's in Computer Science at Shri SSS Jain College for Women, Chennai. She develops applications using Android.

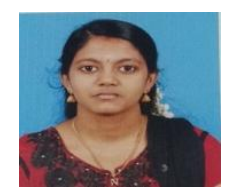

Niranjana $\mathbf{P}$ is doing Master's in Computer Science at Shri SSS Jain College for Women, Chennai. She develops working models using IoT.

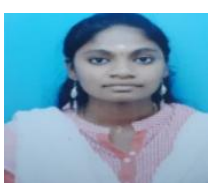

VinithaKumari $\mathbf{R}$ is doing Master's in Computer Science at Shri SSS Jain College for Women, Chennai. She develops applications using Android.

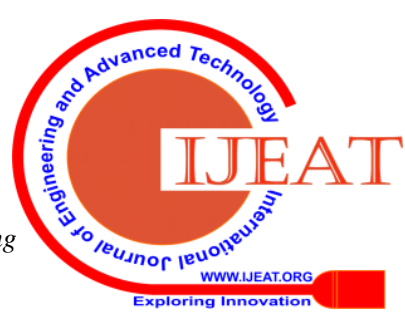

